\title{
Circadian and Sleep Development in Preterm Infants Occurs Independently From the Influences of Environmental Lighting
}

\author{
MAJID MIRMIRAN, ROGER B. BALDWIN, AND RONALD L. ARIAGNO \\ Department of Pediatrics [M.M. R.B.B., R.L.A.], Stanford University School of Medicine, Stanford, CA \\ 94304, U.S.A.; and Netherlands Institute for Brain Research [M.M.], Amsterdam. The Netherlands
}

\begin{abstract}
This study investigated the effect of intermediate nursery illumination on circadian rhythm and sleep development of preterm infants. Preterm infants were randomly assigned to one of two intermediate nursery rooms: a dimly lighted room, the dim (control) group, or a day-night lighted room, the cycled (intervention) group. Continuous rectal temperature and sleep were recorded at $36 \mathrm{wk}$ postconceptional age (before discharge) and at 1 and 3 mo corrected age at home. Forty infants, 21 in the dim group and 19 in the cycled group, were recorded. The clinical demographic data and neonatal scores were similar between groups before the intervention. Circadian rhythms and sleep
\end{abstract}

\section{ABSTRACT}

showed significant development with age, but there was no environmental lighting effect. Circadian and sleep organization seems to develop endogenously in preterm infants. (Pediatr Res 53: 933-938, 2003)
Abbreviations
PCA, postconceptional age
NICU, neonatal intensive care unit
SIDS, sudden infant death syndrome
TLV, time-lapse video

Preterm infants are exposed to continuous low or unpredictable high illumination for several weeks or months in the neonatal intensive care unit (NICU) and intermediate care nursery. These infants are deprived of several potentially important maternal entrainment factors (1-4). This lack of maternal input and exposure to random/unpredictable lighting in the nursery may hinder the development of sleep and circadian rhythms and may adversely influence clinical outcome (5). It is hypothesized that regular lighting in the nursery will improve circadian rhythm development and thereby enhance clinical outcome. Indeed, earlier studies have shown beneficial clinical effects of cycled light in the nursery (6-8). However, the shortor long-term influences of light on development of circadian rhythm were not examined in these studies. A prospective randomized study was initiated to address the hypothesis that cycled light before discharge may improve circadian organization and sleep compared with continuous dim lighting.

Received January 22, 2002; accepted January 6, 2003.

Correspondence: Ronald L. Ariagno, M.D., Department of Pediatrics, Stanford University School of Medicine, 750 Welch Road, Suite 315, Palo Alto, CA 94304, U.S.A.; e-mail: rla@stanford.edu

Supported by National Institutes of Health Grant HD 35754 and RR00070.

DOI: 10.1203/01.PDR.0000061541.94620.12

\section{METHODS}

Preterm infants who were admitted to our nursery at Lucile Packard Children's Hospital at Stanford were eligible. Exclusion criteria were short stay $(<10 \mathrm{~d})$ and transfer to another hospital, major congenital malformations, intrauterine growth retardation, grade 3 or 4 intraventricular hemorrhage, parenchymal injury including periventricular leukomalacia, prenatal infection, or substance abuse. When the clinical condition of an infant in the NICU was stable, he or she was transferred to the intermediate nursery and was randomly assigned to one of two groups: a dimly lighted room, the dim (control) group, or a day-night lighted room, the cycled (intervention) group. We assigned one room of our two-room intermediate care nursery to a continuous dim condition (dim room) in which the lighting remained low (below 20 lux) around the clock. The infant's incubator/bassinet was also covered by a nearly opaque blanket except during feeding or other interventions by parents and caregivers. This is the recommendation of the Neonatal Individualized Developmental Care Program (9), and during the time of this study, dim lighting $24 \mathrm{~h} / \mathrm{d}$ was used as the standard practice at Stanford for all preterm infants. Infants in the cycled room also had their incubator/bassinet covered with the same type of blanket from $1900 \mathrm{~h}$ to $0700 \mathrm{~h}$; however, the blanket was removed from $0700 \mathrm{~h}$ to $1900 \mathrm{~h}$, at which time the room lighting was also turned up to standard lighting levels (approximately 300 lux) to produce a regular light-dark cycled condi- 
tion. Using a digital recorder [Vitalog, see below and Glotzbach et al. (10)], we measured the lighting pattern near the infant's head position inside the incubator/bassinet for both dim and cycled conditions. We regularly checked the rooms' illuminations and crib covers throughout the study period to ensure the implementation of the intervention until discharge.

Body temperature [using a rectal probe (402), YSI, Yellow Springs, OH, U.S.A.] was recorded continuously for up to $3 \mathrm{~d}$ at $36 \mathrm{wk}$ postconceptional age (PCA; just before discharge) as well as at home at 1 and 3 mo corrected age using a digital ambulatory recorder [Vitalog HMS-5000; Respironics, Pittsburgh, PA, U.S.A.; for more details, see Glotzbach et al. (11, 12)]. Each infant's body temperature and environmental illumination were recorded every $10 \mathrm{~s}$.

Twenty-four-hour time-lapse video (TLV) recordings were made in conjunction with the rectal temperature recordings. TLV recording provided noninvasive monitoring of sleep and allowed comparison of the different age groups using the same technology and scoring criteria both in the hospital and at home $(13,14)$. Infrared and low light level cameras allowed recording of the infant even in the dark periods. The camera was focused on the infant's head and upper body for detecting eye movements; facial, head, and hand twitches; startles; and general movements. The $24-\mathrm{h}$ TLV tapes were replayed at 11 times the recording speed for analysis. Quiet and active sleep were scored according to standard criteria $(15,16)$. Briefly, quiet sleep was defined on the basis of eyes closed, regular breathing movement, no movements (except for occasional startles), and no eye movement. Active sleep was scored on the basis of eyes closed, presence of frequent eye movements, facial twitches, and jerky hand and limb movements with irregular breathing. Wakefulness was defined on the basis of eye opening, gross body movement, and cry. All data were scored by an experienced infant sleep researcher (M.M.) who was masked to the experimental condition of the infant. Because most infants (particularly by 3 mo of age) were not left in the crib during the daytime, we were not able to record the 12-h daytime sleep and thus could not measure the day/night ratio of each infant's sleep as a measure of the amplitude of this overt rhythm. However, 12-h nighttime sleep data could be used for comparison between the two groups. Body weights were measured before discharge (at $35 \mathrm{wk}$ postmenstrual age) and at 4 mo.

Statistics were performed using StatView 5.0 (SAS Institute, Cary, NC). Unpaired $t$ tests were used for statistical comparisons with $5 \%$ level of significance (two-tailed) for comparing clinical parameters of the two groups before the start of intervention. These were not the variable of interest as far as the hypothesis of the study is concerned. They were mainly compared statistically to ensure that the randomized groups were balanced and comparable before the start of the intervention. Body temperature amplitude and sleep data of all infants in each group were the main variables of interest; they were analyzed by ANOVA for effects of age and lighting environment and for age by environment interaction. Post hoc Fisher PLSD test was used to compare the amplitude of circadian rhythm of body temperature amplitude and sleep between the cycled and control groups. Unpaired $t$ tests were used for statistical comparisons of weight measurements and to demonstrate that the duration of light intervention was comparable between the two groups (dim and cycled). The Stanford University Institutional Review Board Panel on Human Subjects in Medical Research approved this study, and written informed consents were obtained for all parents.

\section{RESULTS}

We successfully recorded 21 infants in the dim group and 19 infants in the cycled group. All were patients who were admitted to our NICU for prematurity. Mean duration of light intervention was $39 \pm 17 \mathrm{~d}$ for the dim group and $35 \pm 25$ for the cycled group (Table 1). Mean gestational ages were $29.8 \pm$ $1.7 \mathrm{wk}$ and $30.7 \pm 1.3 \mathrm{wk}$; birth weights ranged from 751 to $2280 \mathrm{~g}$ and from 962 to $1817 \mathrm{~g}$ for $\mathrm{dim}$ and cycled groups, respectively. Mean Apgar at 5 min was 8 in both groups. There were no significant differences between the two groups before the intervention for all of these measures or for conventional neonatal scores such as Clinical Risk Index for Babies (17) $(p$ $=0.81$ ); Score for Neonatal Acute Physiology, Version II (18) $(p=0.59)$; Score for Neonatal Acute Physiology, Perinatal Extension, Version II (18) $(p=0.52)$; and unpaired two-tailed $t$ test (Fig. 1).

Figure 2 illustrates the lighting experienced by each group until discharge home. Figure 3 shows representative plots of one infant's body temperature rhythms recorded before discharge and at 1 and 3 mo of age. Figure 4 illustrates the periodogram outcomes of one infant recorded continuously for $3 \mathrm{~d}$ at 36 wk PCA (before discharge) and at 1 and 3 mo corrected age (at home). One can appreciate the predominance of ultradian rhythms with periodicity of approximately $2-4 \mathrm{~h}$ at $36 \mathrm{wk}$, which largely diminish by $3 \mathrm{mo}$ of age with the predominance of a circadian (24 h) rhythm. A subharmonic (12 h) component of circadian rhythm was also found.

At the onset, we planned to analyze all of the data using a periodogram analysis. However, for analyzing all of the data with a periodogram, at least $3 \mathrm{~d}$ of complete data at each age was needed. Only $25 \%$ of our data met this criteria. All recordings were at least $24 \mathrm{~h}$ (Table 1). Therefore, the circadian rhythm amplitude, a well-accepted and established alternative method of analysis, was used. The amplitude of the circadian rhythm was determined by calculating the magnitude of temperature change (maximum minus minimum) for each infant, for each day $(11,12)$. Figure 5 shows the results of the light intervention on the development of circadian rhythms amplitude.

An ANOVA showed a significant age effect $(p<0.0001)$, but no significant environmental light effect ( $p=0.17$ ) or age

Table 1. Duration of light intervention and circadian recording

\begin{tabular}{lccc}
\hline & $\begin{array}{c}\text { DIM } \\
(\text { Mean } \pm \mathrm{SD})\end{array}$ & $\begin{array}{c}\text { Cycled } \\
(\text { Mean } \pm \mathrm{SD})\end{array}$ & $p$ value \\
\hline $\begin{array}{l}\text { No. of days of intervention } \\
\text { No. of days of temperature recording }\end{array}$ & $35 \pm 17$ & 0.68 \\
36 wk PCA & $1.3 \pm 0.8$ & $1.5 \pm 0.7$ & 0.65 \\
1 mo & $1.9 \pm 0.8$ & $1.8 \pm 0.9$ & 0.88 \\
3 mo & $1.9 \pm 0.7$ & $2.0 \pm 1.0$ & 0.81 \\
\hline
\end{tabular}




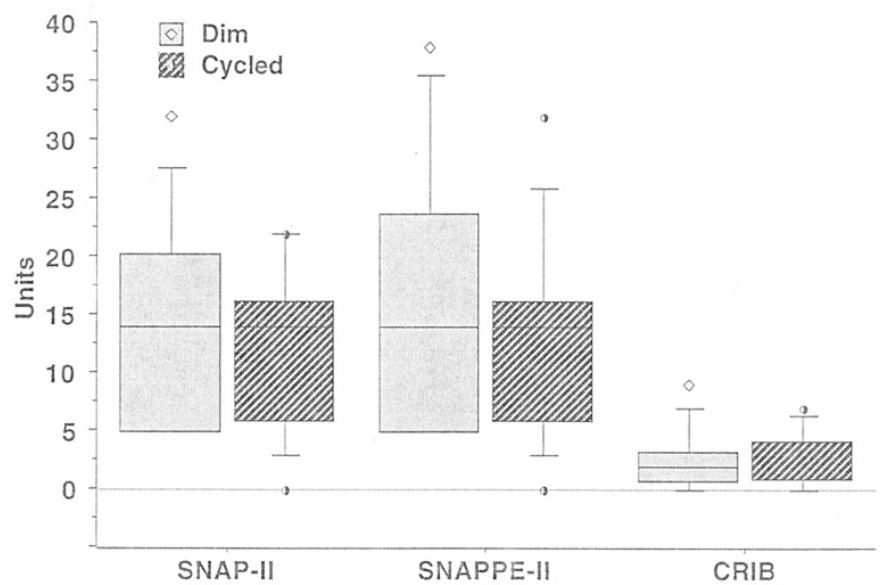

Figure 1. Box plot (median and quartile) presentation of the three different neonatal clinical scores of infants. There were no significant differences between the dim and cycled groups.

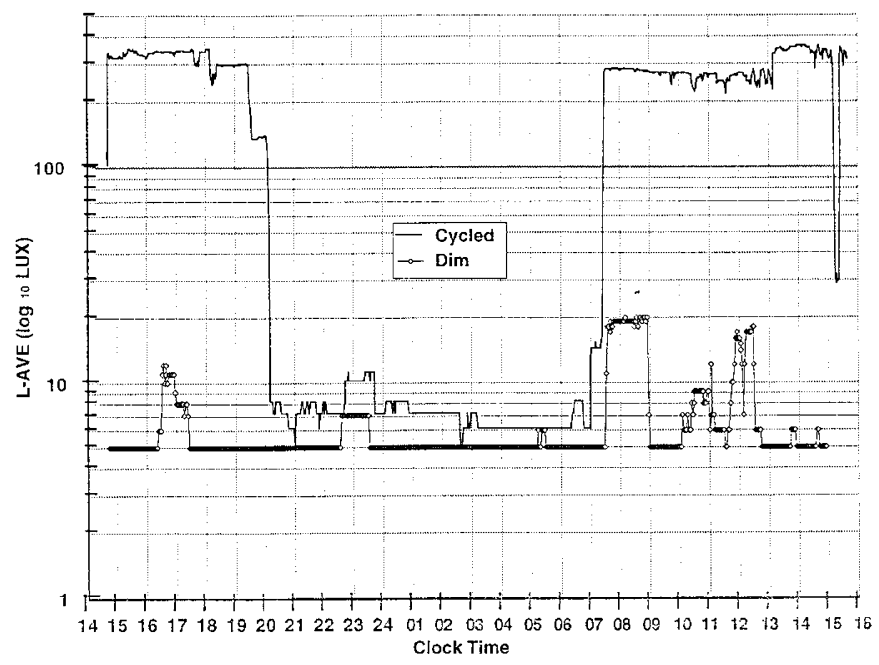

Figure 2. Illumination recorded inside the crib of a representative infant in the cycled nursery (solid line) and another infant in the dim nursery (circles) are plotted as a function of time (six data points per minute). Note the logarithmic scale and that repetitive very low light in the dim condition makes the overlapping circles appear as a thick line.

by environment interaction $(p=0.55)$ on the development of body temperature circadian rhythm amplitude was seen. Post hoc Fisher PLSD test showed significant differences between $36 \mathrm{wk}$ and $1 \mathrm{mo}, 36 \mathrm{wk}$ and $3 \mathrm{mo}$, and $1 \mathrm{mo}$ and $3 \mathrm{mo}(p<$ $0.0001)$. The expected decrease in active sleep and increase in quiet sleep as a function of age in both groups are shown in Figures 6 and 7, respectively. ANOVA for active sleep showed a nonsignificant trend for group effect $(p=0.055)$ with significant age effect $(p=0.04)$ and age by environment interaction $(p=0.03)$. Post hoc Fisher PLSD test showed only significant differences between $36 \mathrm{wk}$ and $1 \mathrm{mo}(p=0.03)$ and $36 \mathrm{wk}$ and $3 \mathrm{mo}(p=0.03)$ but no difference between $1 \mathrm{mo}$ and 3 mo $(p=0.95)$. Comparing dim and cycled groups again showed a nonsignificant trend for differences between the two groups $(p=0.055)$. For quiet sleep, a significant age effect ( $p$ $=0.0002)$ was found with no group $(p=0.54)$ or group by environment interaction $(p=0.64)$. The weights at $35 \mathrm{wk}$ PCA were $1810 \pm 277 \mathrm{~g}$ in the dim versus $1916 \pm 196 \mathrm{~g}$ in the

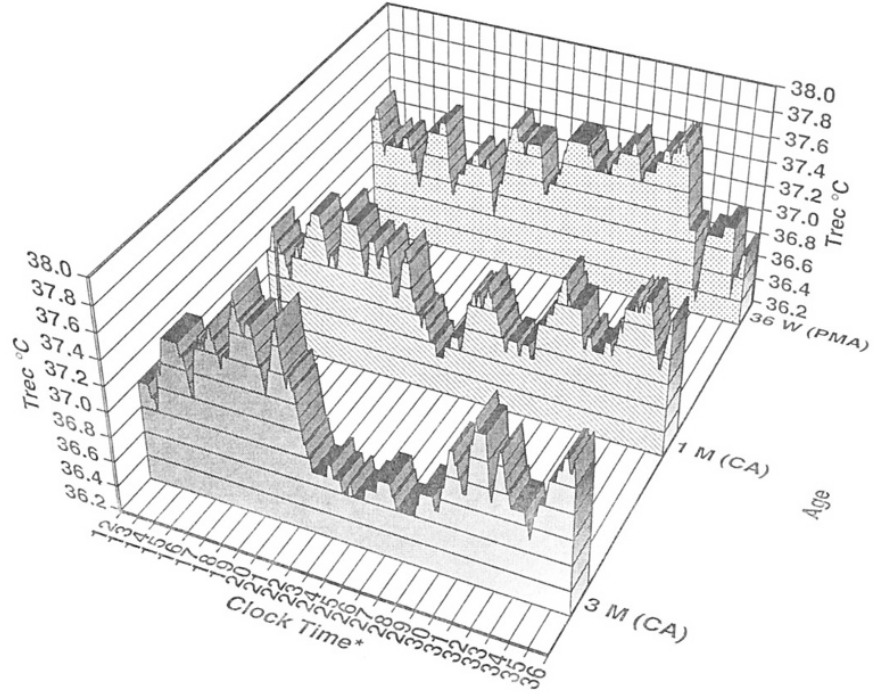

Figure 3. Body temperature of an infant recorded (at $0.1 \mathrm{~Hz}$ ) and averaged over 3 continuous recording days is shown before discharge at 36 wk PCA and at 1 and 3 mo corrected age. Note the temperature trough at night at 1 mo of age becoming more profound by 3 mo.
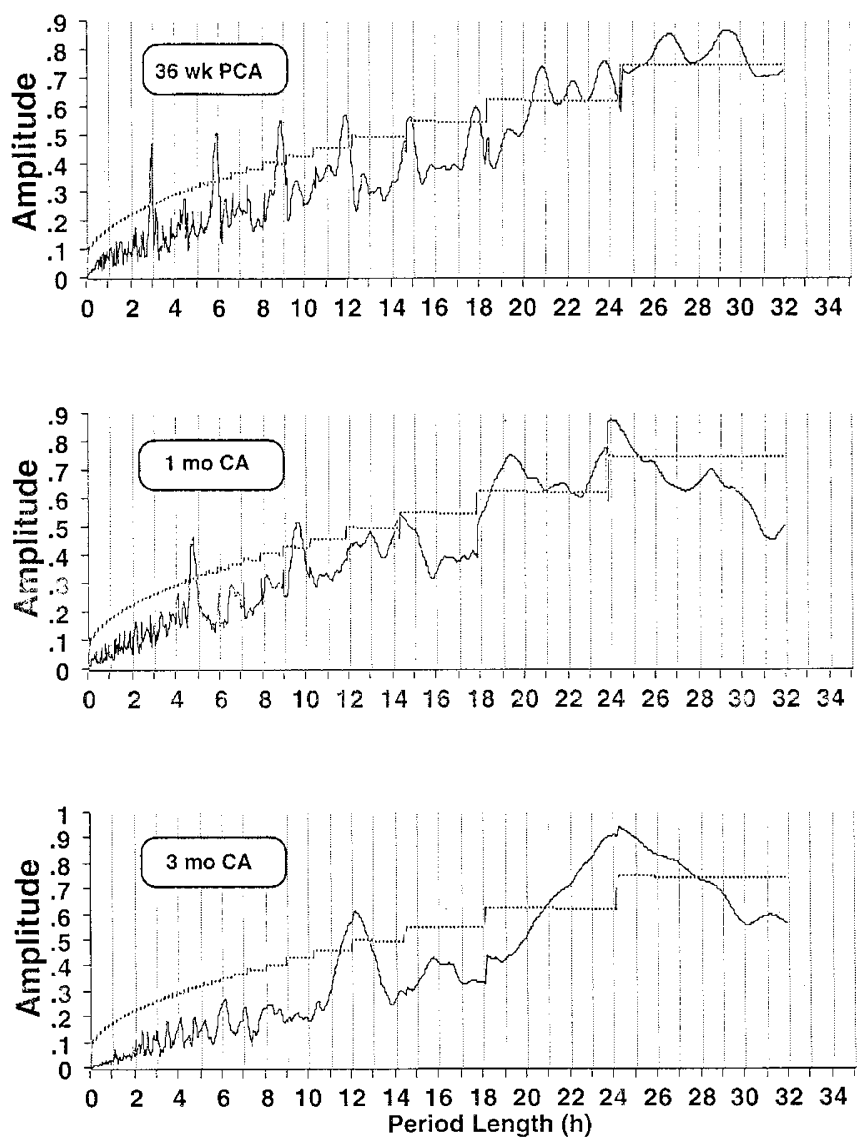

Figure 4. Periodicity of one infant body temperature (solid line) recorded continuously over $3 \mathrm{~d}$ at $36 \mathrm{wk}$ PCA and at $1 \mathrm{mo}$ and 3 mo corrected age. The dotted line indicates the threshold level for significance assuming the signal below this line is a random signal.

cycled group. At 4 mo, weights were also measured (6264 \pm $1393 \mathrm{~g}$ versus $6445 \pm 657 \mathrm{~g})$ and were not significantly different in the two groups (dim versus cycled, respectively). 


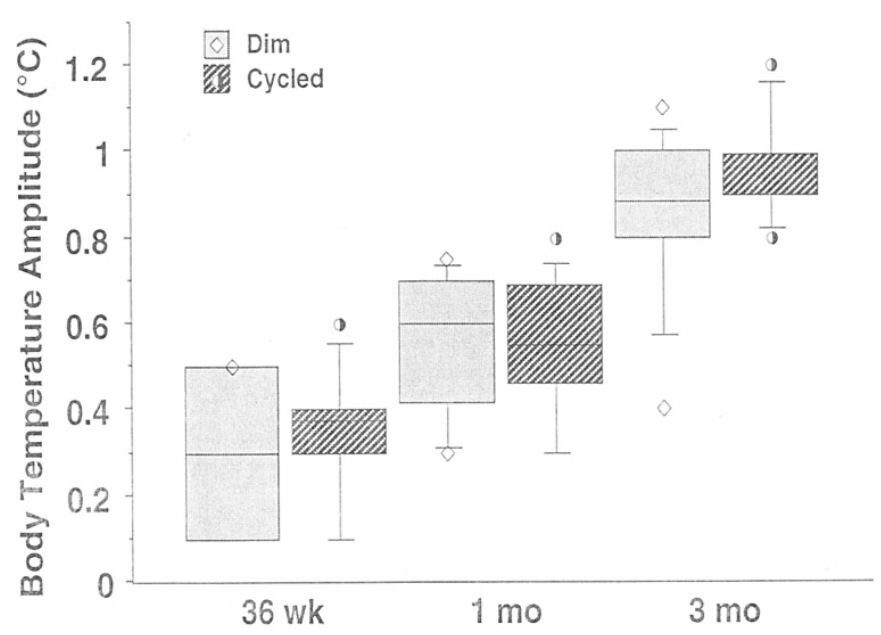

Figure 5. Box plot presentation of body temperature amplitude is shown as a function of age. Note similar development of circadian rhythm amplitude in infants from dim and cycled nurseries. Significant age effects were seen at 36 wk $v s 1 \mathrm{mo}$ and at $1 \mathrm{mo} v s 3 \mathrm{mo}$ ( $p \leq 0.05$; two-tailed $t$ test).

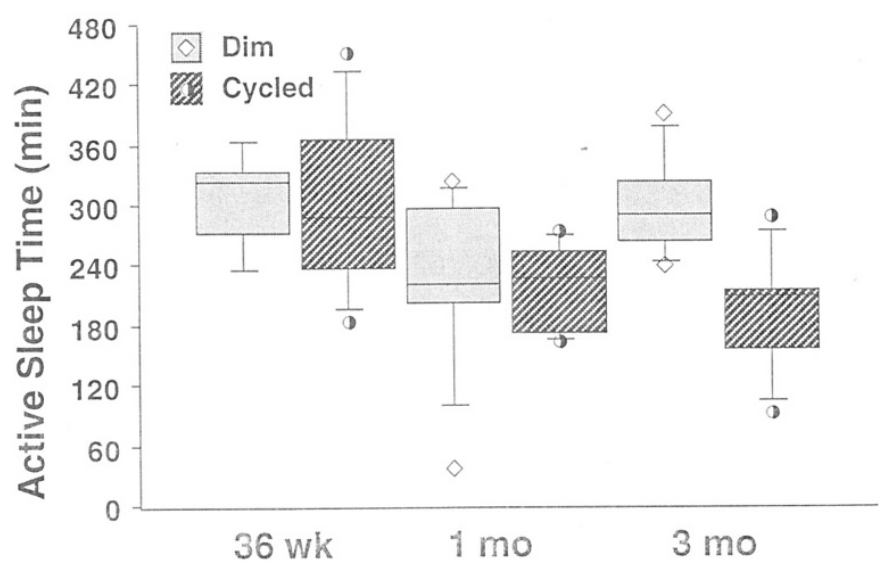

Figure 6. Box plot presentation of total active sleep time during the 12-h night-time (1900 h to $0700 \mathrm{~h}$ ) as a function of age in each group (36 wk vs 3 mo, significant at $p<0.001 ; 1$ mo vs 3 mo, significant at $p=0.0039$, two-tailed $t$ test).

\section{DISCUSSION}

In comparing the body temperature data of these preterm infants with that of our earlier studies of term infants (11), it seems that the circadian rhythms of preterm infants can develop in the absence of maternal and environmental time cues as a function of PCA (i.e. age corrected for prematurity) to a level comparable to term infants at 1 and 3 mo of age (11). The possibility that endogenous perinatal development of circadian rhythms may be based on maturation of the brain more than exposure to an environment has been suggested in human and animal studies $(3,19-22)$. It is important to note that no attempt was made (or, we believed, could reasonably be implemented) to modify the light-dark cycle at home. It could be argued that any effect from intervention in the intermediate nursery was masked by the home environment or that the period of entrainment to cycled light was too short. Because of the clinical condition of the infants at admission and the usual practice of our level 3 NICU, we could not introduce the lighting intervention from birth, which would have been pre-

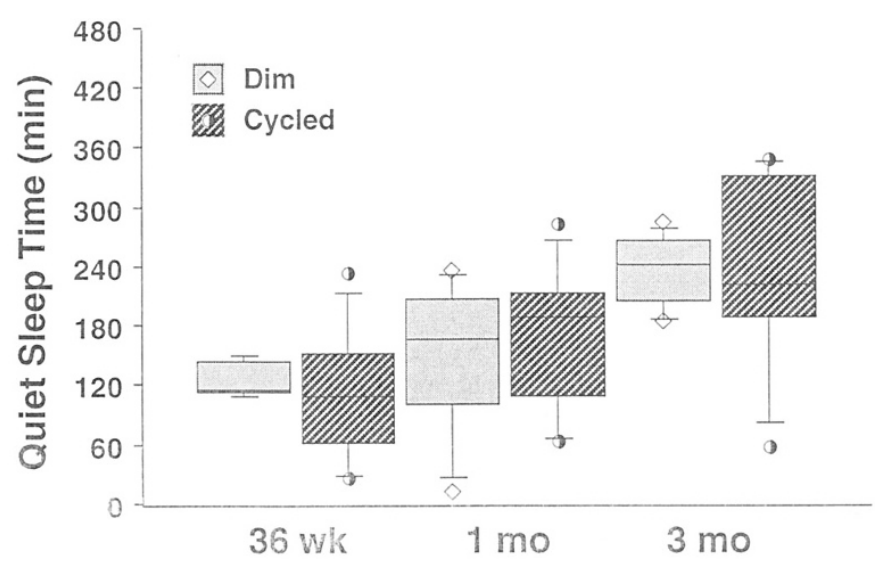

Figure 7. Box plot presentation of total quiet sleep time during the $12-\mathrm{h}$ night-time ( $1900 \mathrm{~h}$ to $0700 \mathrm{~h})$ is shown as a function of age in each group (36 wk vs 3 mo, significant at $p<0.001 ; 1$ vs 3 mo, significant at $p=0.004$, two-tailed $t$ test).

ferred because a longer period of entrainment to cycled light would have been possible. All of our infants received random lighting in the NICU before the start of the intervention. The lighting in our NICU is similar to most other centers in the United States, which varies significantly and in an unpredictable manner from one hour to the next and from bed site to bed site. We have previously published (10) the results of light measurements in the NICU to document this but did not measure the level of light exposure in this study before the intervention. We also could not control for the level of noise in this study. Another limitation of the study is the number and duration of recordings. Given the variability in circadian rhythms, it would have been better if we could have recorded a larger number of infants; however, the sample size was similar to previous studies that suggested clinical effects on sleep, growth, and developmental outcome (6-8). The sample size of 20 was indeed based on the studies by Mann et al. (6) and Miller et al. (7), who studied 21 controls and 20 in the cycled room. We also did a power analysis before starting this study. On the basis of our own previous data at 1 and 3 mo of age, the amplitude of body temperature circadian rhythm would be 0.6 and 0.9 with SD of 0.2 . By assuming that the cycled light may increase this amplitude by $>1$ SD and expecting that the SD remained similar in both group, we did a power analysis and found that 20 subjects in each group will give us the level of significance at $p>0.0005$. Even 15 subjects in each group should be sufficient at $5 \%$ significance.

In support of our data, McMillen et al. (23) also found the circadian rhythm of sleep in the preterm infants similar to term infants entrained after 6 to $10 \mathrm{wk}$ of exposure to the home environment. However, because preterm infants were discharged home at approximately 35 wk PCA in their study, the entrainment to light-dark cycle took place at a significantly earlier PCA (47 wk) in these infants compared with the term group (49 wk). In our study, a shorter duration temperature recording $(<3 \mathrm{~d})$ limited the assessment of the onset of diurnal rhythm and prevented the use of periodogram analysis. Our consent and study design described a 3-d temperature recording; however, in most cases, the parents were unwilling to 
accept the preferred longer duration recording. Nevertheless, a continuous recording of rectal temperature over a 24 -h cycle is an important and reliable measure of circadian rhythm. We were among few investigators to accomplish this and record continuously this endogenous signal for at least one circadian cycle.

The video recording for sleep was done for each infant for a single 24-h period, and only nighttime data could be used for analysis because the infants were more often out of the crib during the day. Shimada et al. $(21,24)$, in a large study, also found no differences between term and preterm infants in the circadian rhythm of sleep, duration of day and night sleep, or the time of onset of the longest sustained sleep time. They showed entrainment to day-night rhythm by 48 wk PCA. Contrary to McMillen, they concluded that environmental factors (both entraining and perturbating) are not able to influence the endogenous time course of circadian rhythm maturation. Their results suggest that a continuous lighting exposure of preterm infants for several weeks before home discharge does not delay the development of sleep-wake circadian rhythms when an appropriate lighting regimen is experienced at home. In a recent study (24), they reported the mean age of the entrainment to light-dark cycle to be $44.8 \mathrm{wk}$ PCA, much earlier than in their earlier publication and very similar to our own data in preterm and term infants $(11,25)$. Again there were no significant differences in the mean age of the entrainment between preterm and term infants in their study (24).

Mann et al. (6) reported increased sleep and weight gain after discharge home in preterm infants exposed to a day-night nursery. The Mann et al. (6) intervention, similar to our study, started after the transfer to the intermediate nursery and lasted for at least $10 \mathrm{~d}$ (mean, $19.5 \pm 6.6$ versus $19.1 \pm 7.5 \mathrm{~d}$ for cycled and control, respectively). Except for one infant in our cycled group, who had $10 \mathrm{~d}$ of intervention before discharge, all of our infants had $>2$ wk intervention; mean days of intervention of 39 and 35 in our study for cycled and dim groups, respectively, were indeed much longer than in the Mann et al. (6) study (Table 1). Both animal and human studies support that even $10 \mathrm{~d}$ of intervention is sufficient to induce an effect on circadian rhythms. Because no differences were found in sleep time before discharge, the Mann et al. (6) findings could not be explained by the fact that these infants were left less disturbed and had more quiet nights in the nursery compared with controls. Miller et al. (7) reported that infants from a nursery with cycled lighting had a greater rate of weight gain, were able to be feed enterally sooner, spent fewer days on the ventilator and on phototherapy, and displayed enhanced motor coordination when compared with matched control infants. Our results do not support the hypothesis that the observed "favorable" effects of a day-night nursery on infant outcome are mediated via sleep and circadian rhythm differences. It is also important to indicate that in the sleep questionnaire study in Mann et al. (6), no day-night effects were found.

One important difference between our study and Mann's was the lighting condition for the controls. Our controls were in a dim nursery, which is the usual Neonatal Individualized Developmental Care Program practice at Stanford during the study, whereas in Mann's study, they were in random bright light. This may account for the lack of differences between the intervention and control groups regarding sleep, circadian rhythm, and weight. One may assume that the condition of the infant in a dim nursery may be superior to random high light commonly experienced in most nurseries particularly in the last decades. This may have decreased the differences between the two groups and thereby minimized the beneficial effect of cycled light in our study.

In the recent Guidelines for Perinatal Care by the American Academy of Pediatrics and the American College of Obstetricians and Gynecologists, the use of a regular day-night cycle in the NICU and intermediate nursery has been noted as potentially beneficial and that additional corroborating data are needed (26). Our sleep and circadian data from the present study do not support the hypothesis by some investigators that the beneficial effects with cycled light are due to improvement in circadian organization and/or an increase in sleep time. Nevertheless, we agree with the recommendations in the Guidelines for Perinatal Care (27) for cycled light, which seem developmentally sound and without apparent adverse effects. The science behind these recommendations requires further study to address the question of whether earlier attainment of diurnal circadian and sleep organization is possible and beneficial for the preterm infant or whether some other mechanism may explain the apparent beneficial effects of cycled light.

Acknowledgments. We thank Margaret A.O. Boeddiker, R.N., and Joan Forte, R.N. It was not possible to carry out this study without the support of our nursing staff and parents. Norman Ruby, Ph.D., advised us in analysis of circadian data. Prof. Byron W. Brown advised us in statistical analysis. Vandana Peddu, M.D., Ellen Hoogeveen, M.D., and medical students Galit Perahia and Anna G. Saporito contributed to this study.

\section{REFERENCES}

1. Reppert SM (ed) 1989 Development of Circadian Rhythmicity and Photoperiodism in Mammals. Perinatology Press, Ithaca, p 262

2. Mirmiran M, Lunshof S 1996 Perinatal development of human circadian rhythms Prog Brain Res 111:217-226

3. Rivkees SA 1997 Developing circadian rhythmicity: basic and clinical aspects. Pediatr Clin North Am 44:467-487

4. Lunshof S, Boer K, Wolf H, van Hoffen G, Bayram N, Mirmiran M 1998 Fetal and maternal diurnal rhythms during the third trimester of normal pregnancy: outcomes of computerized analysis of continuous 24-hour fetal heart rate recordings. Am J Obstet Gynecol 178:247-254

5. Mirmiran M, Kok JH, Boer K, Wolf H 1992 Perinatal development of human circadian rhythms: role of the foetal biological clock. Neurosci Biobehav Rev 16:371-378

6. Mann NP, Haddow R, Stokes L, Goodley S, Rutter N 1986 Effect of night and day on preterm infants in a newborn nursery: randomized trial. BMJ 293:1265-1267

7. Miller CL, White R, Whitman TL, O'Callaghan MF, Maxwell SE 1995 The effects of cycled versus noncycled lighting on growth and development in preterm infants. Infant Behav Dev 18:87-95

8. Brandon DH, Holditch-Davis D, Belyea M 2002 Preterm infants born at less than 31 weeks' gestation have improved growth in cycled light compared with continuous near darkness. J Pediatr 140:192-199

9. Als H, Lawhon G, Brown E, Gibes R, Duffy FH, McAnulty G, Blickman JG 1986 Individualized behavioral and environmental care for the very low birth weight preterm infant at high risk for bronchopulmonary dysplasia: neonatal intensive care unit and developmental outcome. Pediatrics 78:1123-1132

10. Glotzbach SF, Rowlett EA, Edgar DM, Moffat RJ, Ariagno RL 1993 Light variability in the modern neonatal nursery: chronobiologic issues. Med Hypotheses 41:217-224

11. Glotzbach SF, Edgar DM, Boeddiker M, Ariagno RL 1994 Biological rhythmicity in normal infants during the first 3 months of life. Pediatrics 94:482-488

12. Glotzbach SF, Edgar DM, Ariagno RL 1995 Biological rhythmicity in preterm infants prior to discharge from neonatal intensive care. Pediatrics 95:231-237 
13. Goto K, Mirmiran M, Adams MM, Longford RV, Baldwin RB, Boeddiker MA, Ariagno RL 1999 More awakenings and heart rate variability during supine sleep in preterm infants. Pediatrics 103:603-609

14. Mirmiran M, Longford RV, Baldwin RB, Boeddiker MA, Ariagno RL 1997 Timelapse video sleep state determination compared with polysomnography: recording sleep in preterm/term infants. Pediatr Res 41:165A

15. Anders TF, Sostek AM 1976 The use of time lapse video recording of sleep-wake behavior in human infants. Psychophysiology 13:155-158

16. Mirmiran M, Maas Y, Ariagno R (in press) Development of fetal and neonatal sleep and circadian rhythms. Sleep Med Rev

17. Cockburn F, Cooke RWI, Gamsu HR, Greenough A, Hopkins A, McIntosh N, Ogston SA, Parry GJ, Silverman M, Shaw JCL 1993 The CRIB (clinical risk index for babies) score: a tool for assessing initial neonatal risk and comparing performance of neonatal intensive care units. Lancet 342:193-198

18. Richardson DK, Corcoran JD, Escobar GJ, Lee SK 2001 SNAP-II and SNAPPE-I simplified newborn illness severity and mortality risk scores. J Pediatr 138:92-100

19. Coons S, Guilleminault C 1984 Development of consolidated sleep and wakefu periods in relation to the day/night cycle in infancy. Dev Med Child Neuro 26:169-176

20. Mirmiran M, Kok JH 1991 Circadian rhythms in early human development. Early Hum Dev 26:121-128
21. Shimada M, Segawa M, Higurashi M, Akamatsu H 1993 Development of the sleep and wakefulness rhythm in preterm infants discharged from a neonatal care unit Pediatr Res 33:159-163

22. Mirmiran M, Bernardo L, Jenkins SL, Ma XH, Brenna JT, Nathanielsz PW 2001 Growth, neurobehavioral and circadian rhythm development in newborn baboons. Pediatr Res 49:673-677

23. McMillen IC, Kok JSM, Adamson TM, Deayton JM, Nowak R 1991 Development of circadian sleep-wake rhythms in preterm and full-term infants. Pediatr Res 29:381384

24. Shimada M, Takahashi K, Segawa M, Higurashi M, Samejim M, Horiuchi K 1999 Emerging and entraining patterns of the sleep-wake rhythm in preterm and term infants. Brain Dev 21:468-473

25. Mirmiran M, Ariagno RL 2000 Influence of light in the NICU on the development of circadian rhythms in preterm infants. Semin Perinatol 24:247-257

26. American Academy of Pediatrics and The American College of Obstetricians and Gynecologists 1997 Guidelines for Perinatal Care, 4th ed. American Academy of Pediatrics and The American College of Obstetricians and Gynecologists, Elk Grove Village, IL, and Washington, DC, pp 47-48

27. Ariagno RL, Mirmiran M 2001 Shedding light on the very low birth weight infant. J Pediatr 139:476-477 